\title{
A Novel APPI-MS Setup for In Situ Degradation Product Studies of Atmospherically Relevant Compounds: Capillary Atmospheric Pressure Photo Ionization (cAPPI)
}

\author{
Hendrik Kersten, ${ }^{1}$ Valerie Derpmann, ${ }^{1}$ Ian Barnes, ${ }^{1}$ Klaus J. Brockmann, ${ }^{1}$ Rob O'Brien, ${ }^{2}$ \\ Thorsten Benter ${ }^{1}$ \\ ${ }^{1}$ Department of Physical and Theoretical Chemistry, University of Wuppertal, Gauß Str. 20, 42119 Wuppertal, Germany \\ ${ }^{2}$ Department of Chemistry, The University of British Columbia-Okanagan, Kelowna, British Columbia, Canada
}

\begin{abstract}
We report on the development of a novel atmospheric pressure photoionization setup and its applicability for in situ degradation product studies of atmospherically relevant compounds. A custom miniature spark discharge lamp was embedded into an ion transfer capillary, which separates the atmospheric pressure from the low pressure region in the first differential pumping stage of a conventional atmospheric pressure ionization mass spectrometer. The lamp operates with a continuous argon flow and produces intense light emissions in the VUV. The custom lamp is operated windowless and efficiently illuminates the sample flow through the transfer capillary on an area smaller than $1 \mathrm{~mm}^{2}$. Limits of detection in the lower ppbV range, a temporal resolution of milliseconds in the positive as well as the quasi simultaneously operating negative ion mode, and a significant reduction of ion transformation processes render this system applicable to real time studies of rapidly changing chemical systems. The method termed capillary atmospheric pressure photo ionization (cAPPI) is characterized with respect to the lamp emission properties as a function of the operating conditions, temporal response, and its applicability for in situ degradation product studies of atmospherically relevant compounds, respectively.
\end{abstract}

Key words: Ionization, APPI, VUV, Atmospheric chemistry, Ionization mechanisms, Thermodynamic control, Kinetic control

\section{Introduction}

W very year petagrams of volatile organic compounds (VOCs) from anthropogenic and non-anthropogenic sources are emitted into the atmosphere [1,2]. These

Electronic supplementary material The online version of this article (doi:10.1007/s13361-011-0212-y) contains supplementary material, which is available to authorized users.

Correspondence to: Hendrik Kersten; e-mail: hkersten@uni-wuppertal.de compounds readily react with $\mathrm{OH}$ radicals as the starting point of their oxidation pathway through the big "washing machine" troposphere. It is of fundamental interest for life on earth to investigate possible reaction pathways and subsequently formed products of primarily emitted species. On a laboratory scale these degradation product studies are simulated in chamber experiments under well defined and controllable conditions. For monitoring miscellaneous analytical tools are used, e.g., differential optical absorption spectroscopy (DOAS) [3-5], Fourier transform infrared (FTIR) spectroscopy [6, 7], ultraviolet absorption (UV) 
spectroscopy [8, 9], gas chromatography-mass spectrometry (GC-MS) [10], derivatization and diverse sampling methods with subsequent GC-MS [11-13] analysis. The sparingly spread use of in situ MS methods particularly atmospheric pressure ionization (API) MS is mainly due to a major challenge in mass spectrometry: the fate of a charged species between the ionization and the detection step. In API MS, ion transformation processes of the charged species often determine the ion distribution at the detector. Thus, a recorded mass spectrum does not necessarily reflect the initial neutral composition. This is particularly true for direct APPI performed in a conventional API source enclosure with a volume of several tens to hundreds $\mathrm{mL}$. Ionization is often performed with 10.0/10.6 eV photons obtained from Krypton discharge lamps. In this case the vacuum ultraviolet (VUV) radiation from the lamp is nearly quantitatively absorbed by the bulk gas components oxygen, water, and, if applicable, solvent vapors, always present in considerable amounts up to percent ratios. None of these compounds ionize at this wavelength but virtually all photolyze yielding neutral radicals and/or atomic products with considerable quantum yields. Neutral radical species such as atomic oxygen $(\bullet \mathrm{O} \bullet)$ or atomic hydrogen $(\mathrm{H} \bullet)$ have been demonstrated to react close to the gas collision rate with, e.g., radical cations $[14,15]$.

The ion transformations are driven by the strongly changing chemical and physical properties of a neutral molecule with the process of ionization. Initially, the concentration of the newly formed charged species generally deviates from thermodynamic equilibrium. Establishment of the new equilibrium including the charged species is accompanied by molecular structural changes via intra- or intermolecular processes, i.e., the corresponding concentrations within the mixture change. The extent of such ion transformation processes depends on the chemical properties of the participating compounds, particularly the equilibrium constants involved. The composition of the matrix and the number of collisions between ionization and detection determine whether or not a fully equilibrated mixture enters the collision free analyzer region. In conventional large volume API sources the minimum transit time to the collision free region is on the order of tens of ms $[16,17]$. Within this time all molecular species have undergone at least $10^{6}$ collisions, which is sufficient to reach a fully equilibrated state. ${ }^{1}$ This basically causes two major issues for analytical API MS of unknown composites: (1) ions are detected at significantly differing masses than their neutral counterpart, hence a mass spectrum is affected by artificial

\footnotetext{
${ }^{1}$ In a very nice review paper on API MS from 1981, Carroll et al. have thoroughly described this situation: "Another way of comparing API and CI routes of reaction and ion products is in terms of rates of reaction and equilibrium concentrations. The ion products observed under CI conditions are a reflection of reaction rates and not of the concentrations existing under equilibrated conditions. The ion products observed under API conditions are all formed by relatively fast gas-phase reactions, but the mass spectra reflect equilibrated conditions rather than rates of reaction."'[18]
}

signals which are produced by the analytical method itself [19]; (2) ion molecule reactions leading to a thermodynamically controlled (thermally equilibrated) ion distribution lead to a loss of mass spectrometric information in favor of a reduced set of energetically favored species. Despite these downsides, ionizing at elevated pressure clearly results in higher ionization efficiencies due to the higher neutral analyte concentration.

Furthermore, APPI is a very attractive direct ionization method provided that ion transformation reactions, particularly with the inherently generated neutral radicals due to VUV photolysis, are suppressed. One feasible approach is minimization of the dwell time of primarily generated ions in the collision dominated high pressure region upstream of the analyzer. The ion transfer capillary, characterized as a high pressure environment throughout its entire length, is located closest to the virtually collision free analyzer region. Unfortunately, commercially available APPI lamps do not allow efficient irradiation of the capillary gas flow. Therefore, miniature VUV lamps are required. Such lamps need to deliver spatially precisely adjustable, highly efficient VUV radiation on a small and well defined illuminated area within the capillary.

Generation of radiation in the VUV wavelength regime requires the excitation of neutral or ionized atoms/molecules, typically rare gas atoms, into energetically higher atomic/ molecular states. Numerous strategies have been applied, such as multi-photon excitation with laser light [20], collisions with accelerated electrons/ions/particles [21-24], or various electrical discharges [25-29]. In general, the implementation of a gas discharge driven VUV light source in a mass spectrometric setup is impeded by the necessity of separating the discharge region from the sample gas flow into the mass spectrometer. This is mainly done to prevent the discharge from being perturbed or even quenched, and to enable operation of low pressure discharges to sustain a stable VUV emission. In most cases $\mathrm{MgF}_{2}$ or $\mathrm{LiF}$ windows are used for physical separation. However, these windows not only restrict the transmission of VUV light below the optical cut off $\left(\mathrm{MgF}_{2}: 110 \mathrm{~nm}\right.$; LiF: $\left.105 \mathrm{~nm}\right)$ but also severely reduce the transmission efficiencies above the cutoff [30-32]. However, no conventional window material with lower cutoff wavelength is commercially available. Furthermore, in insufficiently sealed discharge systems the surface of the window will eventually become opaque upon prolonged lamp operation.

In this work we introduce an atmospheric pressure photoionization mass spectrometry (APPI MS) approach that is effectively reducing the extent of ion transformation processes with only minor loss of neutral analyte density. This approach relies on ionization within the mass spectrometer transfer capillary using a custom miniature VUV lamp. The characteristics of a windowless miniature pulsed VUV spark discharge lamp and the effects of its location within the setup will be discussed in detail. Additionally, a discussion on the performance and future prospective on the basis of exemplary atmospherically relevant in situ degra- 
dation product studies will be given. Since we are not aware of any report on an ionization source embedded within the MS transfer capillary, we have chosen the term capillary atmospheric pressure photo ionization (cAPPI) for this approach. It is proposed to generally precede the established acronym of the ionization method used by a lower case $c$ when ionizing inside the transfer capillary gas flow.

\section{Experimental}

\section{Chemicals}

Acetonitrile (ACN) was obtained from Fisher Scientific, Waltham, MA, USA. Benzene and p-xylene were purchased from Merck KGaA, Darmstadt, Germany and from Fluka, Buchs, Switzerland, respectively. Nitrogen oxide (NO) was from Air Liquide Deutschland GmbH, Düsseldorf, Germany, with a stated purity of $99.5 \%$. Argon and synthetic air were from Gase.de, Sulzbach, Germany, with a stated purity of $99.999 \%$ vol. A mixture of 17 oxygenated VOCs in synthetic air was prepared in-house and stored in a compressed gas cylinder. The mixing ratios ranged between 10 and $220 \mathrm{ppbV}$ and were confirmed via calibrated GC-MS analysis. Methylnitrite (MeONO) was synthesized as described in [33] and stored at $-78^{\circ} \mathrm{C}$. All solvents were of analytical or chromatographic purity, all other chemicals of highest purity available, and were used without further purification.

\section{Instrumentation and Methods}

Photoreactor and Experimental Procedure for Degradation Studies The degradation experiments were performed in a $1080 \mathrm{~L}$ quartz glass reactor as described in $[34,35]$. Briefly, the chamber is of $6.2 \mathrm{~m}$ length and has an i.d. of $0.47 \mathrm{~m}$ and is evenly surrounded by 32 super actinic fluorescence lamps $(320 \mathrm{~nm}<\lambda>480 \mathrm{~nm})$ and 32 low pressure Hg-lamps $\left(\lambda_{\max }=\right.$ $254 \mathrm{~nm}$ ). Both ends are closed by aluminum flanges providing versatile access to the reactor via multiple connections. The reactor is equipped with long-path White type absorption optics (484.7 m path length) coupled to an FTIR spectrometer. For typical $\mathrm{OH}$ radical initiated degradation experiments at high $\mathrm{NO}_{\mathrm{x}}$ conditions, around $1 \mathrm{ppmV}$ of the compound to be investigated, 2-5 ppmV $\mathrm{NO}$ and 2-5 ppmV MeONO are injected into the photoreactor and backfilled with synthetic air to atmospheric pressure. Switching on the superactinic fluorescent lamps induces the production of $\mathrm{OH}$ radicals via the photo dissociation of $\mathrm{MeONO}$ followed by a subsequent reaction cascade with $\mathrm{O}_{2}$ and $\mathrm{NO}$ :

$$
\begin{array}{rlr}
\mathrm{CH}_{3} \mathrm{ONO}+\mathrm{h} v(\lambda>360 \mathrm{~nm}) & \rightarrow \mathrm{CH}_{3} \mathrm{O} \cdot+\mathrm{NO} \cdot & (\text { Rxn.1) } \\
\mathrm{CH}_{3} \mathrm{O} \cdot+\mathrm{O}_{2} & \rightarrow \mathrm{HCHO}+\mathrm{HO}_{2} \cdot \\
\mathrm{HO}_{2} \cdot+\mathrm{NO} \cdot & \rightarrow \mathrm{OH} \cdot+\mathrm{NO}_{2} \cdot
\end{array}
$$

The experiment is typically finished within 30 to $40 \mathrm{~min}$ with $50 \%$ to $60 \%$ degradation of the initial compound.
Considering starting concentrations of around $1 \mathrm{ppmV}$, oxygenated products in the ppbV range are expected.

MS Sampling Unit A sampling glass tube (Figure 1 a: 2) of $20 \mathrm{~cm}$ length with an i.d. of $8 \mathrm{~mm}$ extends into the reactor from a gate valve (Figure 1 a: 3 ), which is directly mounted on the aluminum flange on the outside of the reactor. A second glass tube of equivalent dimensions guides the sample further downstream into the custom laminar-flow ion source (LFIS), as shown in Figure 1a: 5 and 6 [36]. This transfer tube is surrounded by an aluminum housing with a sheath gas inlet port (Figure 1a: 4). The continuous sample flow from the reactor is solely determined by the choked flow of the mass spectrometer's transfer capillary and is $1.4 \mathrm{~L} / \mathrm{min}$. Considering the dimensions of the entire tubing system the transit time of a sample from the reactor to the entrance of the MS is about $0.9 \mathrm{~s}$. The pressure in the reactor is maintained by providing a continuous flow of synthetic air matching the amount sampled. The resulting dilution in the chamber amounts to $8 \%$ after $60 \mathrm{~min}$.

Mass Spectrometer All mass spectrometric measurements were performed with an esquire 6000 quadrupole ion trap (Bruker Daltonik GmbH, Bremen, Germany) equipped with a custom laminar-flow ion source (Figure 1a: 6), which was first introduced in [36]. Briefly, the analyte gas flow enters the source at a $10^{\circ}$ angle to the main tube axis $(20 \mathrm{~cm}$ long, i.d. of $4 \mathrm{~mm}$ ), and is transferred through an acutely angled cone with an outlet diameter of $0.8 \mathrm{~mm}$ into the transfer capillary (Figure 1a: 9) of the MS. A port located on top of the laminar-flow ion source (Figure 1a: 8) allows for VUV irradiation of the sample gas flow. In addition, selective and sensitive detection of poly aromatic hydrocarbons (PAHs) experiments is performed with the integrated atmospheric pressure laser ionization setup (APLI) [37-39]. An optical delivery stage (Figure 1a: 11) directs the laser beam of a diode pumped UV solid state (DPSS) Nd:YAG laser (FQSS 266-50; CryLas, Berlin, Germany) (Figure 1a: 10) coaxially into the ion source [40], i.e., along the propagation direction of the sample gas flow. The entire laminar-flow ion source (Figure 1a: 6) together with the transfer unit from the reactor (Figure 1a: 5) can be pumped down to roughly 10 mbar in a few seconds by shutting off the supply gas with the gate valve closed (Figure 1a: 3).

VUV Photo Ionization Setup Within the Transfer Capillary The observation of superimposed ion-molecule reactions in conventional API MS (also within the LFIS) evoked the need for a novel ionization approach. The working principle of this newly developed cAPPI setup was first introduced in [41]. A windowless miniature pulsed DC-spark discharge VUV lamp is embedded in the ion transfer capillary (cf. Figure 1b). The capillary is a central part of the first vacuum stage unit between the atmospheric and low pressure region 
(a)

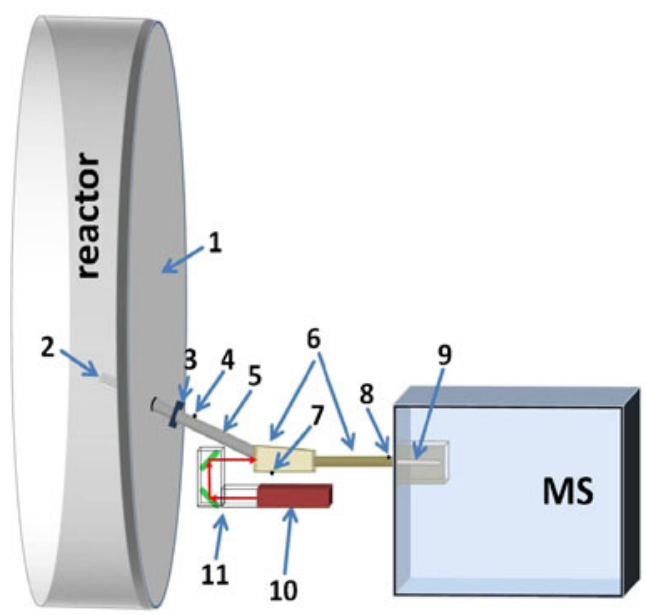

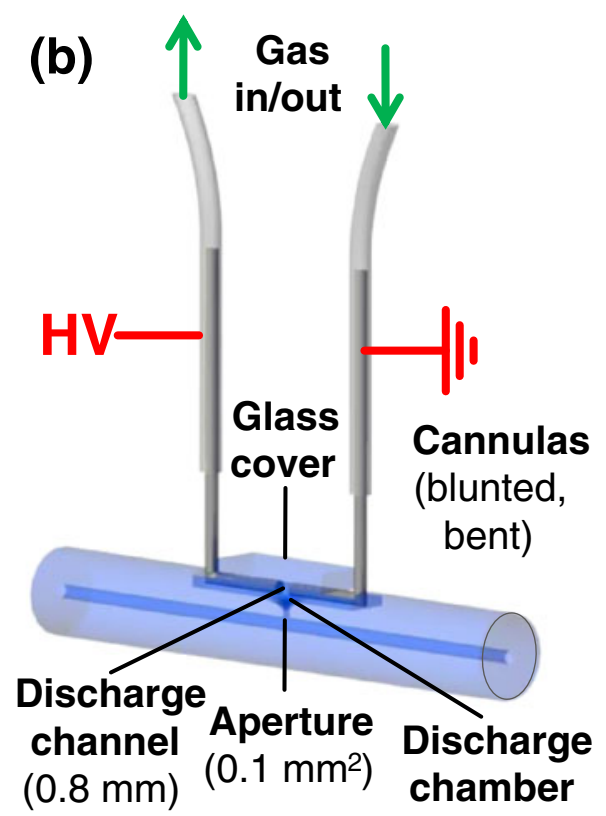

Figure 1. (a) Experimental setup for degradation studies: (1) Aluminum flange of the reactor; (2) sampling glass tube; (3) gate valve; (4) sheath gas inlet; (5) transfer unit (glass tube, surrounded by an aluminum housing, allows for sheath gas supply); (6) laminar-flow ion source [36]; (7) port for pressure measurement; (8) VUV radiation inlet stage; (9) transfer capillary unit with the custom APPI setup; (10) DPSS laser; (11) laser optics (mirrors). (b) Custom APPI setup within the transfer capillary separating the atmospheric pressure region and the low pressure region ( 4 mbar) of the first differential pumping stage

of the mass spectrometer. The transfer capillary is $18 \mathrm{~cm}$ long with an o.d. of $6.5 \mathrm{~mm}$ and an i.d. of $0.6 \mathrm{~mm}$. Two conical flutes of $8.0 \mathrm{~mm}$ length and $2.0 \mathrm{~mm}$ depth are cut into the capillary along the main axis, merging in a bore of $2.3 \mathrm{~mm}$ in diameter and $2.5 \mathrm{~mm}$ depth (discharge chamber). In the center of the discharge chamber an aperture of less than $1 \mathrm{~mm}^{2}$ is cut into the inner tube of the transfer capillary. Two bent and blunted cannulas are used as electrodes and for a continuous discharge gas supply. They are inserted into the two flutes symmetrically on top of the aperture with a distance of $0.8 \mathrm{~mm}$ separating the cannula ends. With this arrangement, the distance from the discharge region to the sample gas flow into the mass spectrometer is only $1.0 \mathrm{~mm}$, and the irradiated area is less than $1 \mathrm{~mm}^{2}$. The electrodes, a glass cover on top of the discharge region, and the cable for the power supply are cemented (cement no. 31; Sauereisen, Pittsburgh, PA, USA) into a compact, sealed and electrically safe design. A continuous argon flow of typically 100 $500 \mathrm{~mL} / \mathrm{min}$, which also enhances cooling of the metal, is supplied through the grounded anode. The gas outlet through the opposite high voltage cathode is connected to the rough pump of the mass spectrometer via a needle valve and to a manometer, allowing for the adjustment of the pressure difference between the discharge chamber and the static pressure inside the transfer capillary. A custom designed high voltage circuit board (DD20_10 C-Lader; Hartlauer Präzisions Elektronik GmbH, Grassau, Germany) was used as power supply. A typical pulse repetition rate of $1500 \mathrm{~Hz}$ was applied. The pulse-to-pulse stability and the discharge current amplification were increased when the trigger pulse width of the high voltage module was adjusted to exceed the discharge pulse duration by about $30 \mu \mathrm{s}$.

Optical Emission Spectroscopy (OES) All NIR/VIS/UV $(1100 \mathrm{~nm}-200 \mathrm{~nm})$ spectroscopic measurements were performed with a high resolution fiber optic spectrometer AvaSpec-3648 (Avantes BV, Eerbeek, The Netherlands) connected to a broad transparent fiber optic (ZFQ-9866; Ocean Optics, Dunedin, FL, USA). Scans between 200 and $105 \mathrm{~nm}$ were performed with an ARC VM-502 VUV spectrometer (Acton Research Corporation, Acton, MA, USA) equipped with a $\mathrm{LiF}$ window ( $2 \mathrm{~mm}$ thick) at the radiation light entrance and a custom micro channel plate (MCP) unit at the exit. The MCP signal was recorded by a digital multimeter (VA18B; Shanghai Yihua V\&A Instruments Co., Ltd., Shanghai, China) and transferred at $2 \mathrm{~Hz}$ to a personal computer as time/signal data points. The optical spectrum was obtained via post processed time/wavelength conversions. The scan speed was $0.1 \mathrm{~nm} / \mathrm{s}$ with an optical resolution of $1.7 \mathrm{~nm}$ (FWHM; $10 \mu \mathrm{m}$ entrance and exit slit widths). Due to the impracticability of sampling VUV spectra within the transfer capillary a modified design of the miniature spark discharge lamp was used for VUV spectroscopic measurements, however, with basically identical dimensions and discharge characteristics. The temporal evolution of a single spark in the UV/VIS was investigated with a photodiode (SD 200-12-22-041; Advanced Photonics, Inc., Camarillo, CA, USA) operated in reversed-biased mode and connected to an oscilloscope (TDS 1012; Tektronix, 
Inc., Wilsonville, OR, USA). Visualization and data processing was done with a custom program based on LabVIEW 7.1 (National Instruments, Austin, TX, USA).

Limit of Detection (LOD) Determinations The limit of detection for benzene was determined by adding a $0.1 \mathrm{M}$ ACN solution ( $\mu \mathrm{L}$-stepwise) into the photoreactor. The LOD for 2-butanone was established by combining a carrier gas flow of synthetic air with a flow of a gas mixture containing 2-butanone at a mixing ratio of $96 \mathrm{ppbV}$ in nitrogen. The main gas supply was provided through a mass flow controller (1179A Mass-Flo-Controller, $2000 \mathrm{sccm}$; MKS Instruments, Andover, MA, USA), which was connected to the sheath gas inlet port of the transfer unit (Figure 1a: 4). The analyte flow was connected to the entrance of the transfer unit (Figure 1a: 5) via a $10 \mathrm{sccm}$ mass flow controller (1179A Mass-FloController, $10 \mathrm{sccm}$; MKS Instruments, Andover, MA, USA). Both mass flow controllers were connected to a 647 C multi-gas-controller unit (MKS Instruments, Andover, MA, USA). Gas flow calibrations were performed with either a wet meter TG05 (Ritter Apparatebau GmbH and Co. KG, Bochum, Germany) or a calibrated bubble counter.

\section{Results and Discussion}

\section{Characterization of the Transfer Capillary and Different Ionization Positions}

Detailed investigations revealed that well known empirical equations [42, 43], developed for describing the fluid dynamical behavior of large tubing systems, are to a good approximation also valid for the dimensions of a transfer capillary $(0.5 \mathrm{~mm}-0.6 \mathrm{~mm}$ i.d.; $18 \mathrm{~cm}$ length): (1)The experimentally observed downstream pressure dependency of the flow through the capillary matched the calculated data within experimental error; (2)the experimentally determined static pressure $p_{\text {static }}$, measured through small holes, which were drilled into the capillary body (cf. Figure 1b), was within $\pm 2 \%$ of the calculated static pressure; (3) the theoretically determined ion transit time through the capillary is $1.5 \mathrm{~ms}$, the experimentally determined time is $1.2 \mathrm{~ms}$ for the fastest ions. According to our present investigations, the gas flow through a transfer capillary (gas temperature room temperature $=$ constant) is best characterized as a fully developed turbulent, choked flow ranging between 0.8 and $1.4 \mathrm{~L} / \mathrm{min}$ at an upstream stagnation pressure of $\mathrm{p}_{0}=$ 1000 mbar and a downstream background pressure of $\mathrm{p}_{1}<$ 100 mbar. Most API mass spectrometers are operated with $\mathrm{p}_{1}$ in the low mbar range. The minimum or critical capillary pressure $p_{\text {crit }}[\mathrm{mbar}]$ is reached where the gas velocity reaches sonic speed, and typically ranges between $\mathrm{p}_{\text {crit }}=$ 180-220 mbar. For our calculations we assumed the critical pressure to be reached at the capillary exit, hence the gas enters with $p_{\text {crit }}$ into $p_{1}$ of the first differential pumping stage.

Static Pressure, Velocity Distribution, and Transit Time For a calculation of the transit time of a molecule in the transfer capillary, the following experimental data are required: (1) the length L [cm] of the capillary, (2) the choked flow Q [L/s], (3) the downstream background pressure $\mathrm{p}_{1}[\mathrm{mbar}]$, and (4) the upstream stagnation pressure $\mathrm{p}_{0}$ [mbar]. The latter is critical, since turbulences around the entrance of the capillary result in significantly enhanced pressure drops, i.e., pressure measurements at some distance from the capillary entrance might not properly reflect $\mathrm{p}_{0}$. Due to the conically shaped reducer of the laminar-flow ion source at the transit to the transfer capillary, such turbulences are greatly minimized [36]. Using this set-up the measured pressure (cf. Figure 1a: 7) reflects $p_{0}$ to a good approximation. With this fundamental information, the i.d. d [cm] of the transfer capillary is repeatedly calculated (with an accuracy of $\pm 1 \cdot 10^{-4} \mathrm{~cm}$ ) using Equation (1) [42] until the result matches with the experimentally measured choked flow $\mathrm{Q}[\mathrm{L} / \mathrm{s}]$.

$$
Q=\frac{134 \cdot d \cdot\left(\frac{d^{3}}{L} \cdot \frac{p_{0}^{2}-p_{1}^{2}}{2}\right)^{\frac{4}{7}}}{p_{0}}
$$

Then, the minimum exit or critical pressure is calculated using Equation (2) [42].

$$
p_{\text {crit }}=\frac{4.51 \cdot\left(\frac{d^{3} \cdot p_{0}^{2}}{2 \cdot L}\right)^{\frac{4}{7}}}{d}
$$

The static pressure $\mathrm{p}_{\text {static( } \mathrm{x})}$ [mbar] evolution along the transfer capillary is calculated according to Equation (3) [43]:

$$
p_{\text {static }(x)}=p_{0} \cdot \sqrt{1-\left(1-\frac{p_{\text {crit }}}{p_{0}}\right) \cdot \frac{x}{L}}
$$

with $\mathrm{x}[\mathrm{cm}]$ as the position of the capillary, relative to the entrance. The velocity distribution $\mathrm{c}_{\mathrm{x}}$ is then obtained by Equation (4) [43]:

$$
c_{(x)}=\frac{p_{0}}{p_{\text {static }(x)}} \cdot c_{(0)}
$$

with $\mathrm{c}_{(0)}$ as the entrance velocity, which is simply derived from dividing the flow $\mathrm{Q}$ by the area cross-section of the capillary (assuming the fitted diameter). Finally, the residence time $t_{\text {res }}$ of an ion within the transfer capillary is derived from numerical 
integration over the fraction of $\mathrm{x} / \mathrm{c}_{(\mathrm{x})}=\mathrm{t}_{\mathrm{res}(\mathrm{x})}$ according to Equation (5)

$$
t_{\text {res }}=\sum_{x=\text { ionization position }}^{x=L} t_{\text {res }(x)}
$$

It is noted that Equations (1) and(2) hold true for air as the bulk gas at $293 \mathrm{~K}$, and Eqs. 3-5 assume isothermic conditions, i.e., constant gas temperature inside the capillary, despite the expansion process. This behavior has been experimentally verified; the exit gas temperature of the capillary flow is approximately the same as the wall temperature and largely independent of the upstream bulk gas temperature [44]. This coincides very well with the experimental conditions of a common atmospheric chemistry degradation experiment when sampling from the reactor held at room temperature. In Figure 2, typical results of these calculations are shown.

Additional experiments on the ionization position closest to the upstream capillary port with the laminar-flow ion source set-up (cf. Figure 1a: 8) resulted in a total transit time to the exit port of the capillary of $5 \mathrm{~ms}$. It was shown earlier that minimum transit times of $5 \mathrm{~ms}$ are also obtained with commercially available API sources [16]. As can be seen from the results in Figure 2 the approach of ionizing within the capillary flow reduces transit times in the high collision rate region by a factor of 250 with an accompanying reduction in the analyte density of only a factor of 4 . Thus the ionization efficiency is greatly improved.

Impact of Different Ionization Positions on the Ion Signal Distribution In Figure $3 \mathrm{a}$ and $\mathrm{b}$, the effect of reduced ion dwell times within the capillary is demonstrated using the negative ion mode. A degradation experiment with $p$-xylene was repeated three times at three different ionization positions; within the laminar-flow ion source (cf. Figure 1a: 8), and at position 15 and $17.5 \mathrm{~cm}$ on the transfer capillary, with corresponding transit times of $5,0.13$, and $0.02 \mathrm{~ms}$, respectively (cf. Figure 2 right). Figure 3 a shows negative ion mass spectra at the start of the experiment, with all chemicals
(1 ppmV p-xylene, 5 ppmV MeONO, 3 ppmV NO) injected into the photoreactor. The most abundant peak in each spectrum $(\mathrm{m} / \mathrm{z} 62)$ is assigned to the $[\mathrm{M}-\mathrm{H}]^{-}$ion of $\mathrm{HNO}_{3}$, which is always present due to its formation as a degradation byproduct for runs under $\mathrm{NO}_{\mathrm{x}}$ rich conditions (see also Rxn. 3):

$$
\mathrm{HO} \cdot+\mathrm{NO}_{2} \cdot+\mathrm{M} \rightarrow \mathrm{HNO}_{3}+\mathrm{M}
$$

Figure $3 \mathrm{~b}$ shows mass spectra of a sample from the photoreactor after $25 \mathrm{~min}$ of the degradation experiment. The spectrum obtained from the ionization position within the laminar-flow ion source $(5 \mathrm{~ms})$ remained virtually unchanged. In contrast, the spectra obtained from the ionization positions within the transfer capillary show significantly more signals, which are assigned to oxygenated products of the degraded p-xylene. The extensive loss of MS information along the $5 \mathrm{~ms}$ transit time is attributed to secondary ion transformation processes of the types:

$$
\begin{aligned}
& \mathrm{M} \cdot-/[\mathrm{M}-\mathrm{H}]^{-}+\mathrm{HNO}_{3} \rightarrow \mathrm{MH} \cdot / \mathrm{M}+\mathrm{NO}_{3}{ }^{-}(\mathrm{Rxn} .5) \\
& \mathrm{M}^{\cdot-} /[\mathrm{M}-\mathrm{H}]^{-}+\mathrm{P} \cdot{ }^{+} /[\mathrm{P}+\mathrm{H}]^{+} \rightarrow \mathrm{M} / \mathrm{MH}+\mathrm{P} \quad \text { (Rxn.6) } \\
& \mathrm{M}^{\cdot-} /[\mathrm{M}-\mathrm{H}]^{-}+\mathrm{P} \cdot+/[\mathrm{P}+\mathrm{H}]^{+} \rightarrow \mathrm{MP} / \mathrm{MPH} \quad \text { (Rxn.7) }
\end{aligned}
$$

with $M$ and $P$ being any chemical species present in the matrix. In reaction 5 , the species with the lower proton affinity $\left(\mathrm{HNO}_{3}\right)$ is favored, and reactions 6 and 7 consider charge neutralization. In other words, the ion signal distribution is thermodynamically equilibrated within $5 \mathrm{~ms}$ and mass spectrometric information is lost, whereas ionizing within the transfer capillary in fact shifts the system towards kinetically controlled ion signal distributions, hence more mass spectrometric information is preserved. It is noted that in any conventional API source operating with transfer capillaries as pressure reduction stages, transit times of at least $5 \mathrm{~ms}$ to the collision-free region are necessary; average dwell times are in fact 50-100 ms [17]. Consequently, samples from degradation experiments under $\mathrm{NO}_{\mathrm{x}}$ rich conditions are not amenable to investigation using the negative ion mode with common API-MS methods.

\begin{tabular}{|c|c|c|}
\hline $\begin{array}{l}\text { ionization } \\
\text { position [cm] }\end{array}$ & $\begin{array}{c}\text { static pressure } \\
\text { [mbar] }\end{array}$ & $\begin{array}{l}\text { dwell time } \\
\text { [ms] }\end{array}$ \\
\hline 0.0 & 1003 & 1.55 \\
\hline 3.0 & 920 & 1.19 \\
\hline 6.0 & 828 & 0.87 \\
\hline 9.0 & 725 & 0.58 \\
\hline 12.0 & 605 & 0.33 \\
\hline 15.0 & 453 & 0.13 \\
\hline 17.0 & 314 & 0.03 \\
\hline 17.5 & 268 & 0.02 \\
\hline
\end{tabular}

The impact on the positive ion signal distribution upon changing the ionization position is demonstrated in Figure $3 \mathrm{c}$. Both spectra were recorded at the same reaction

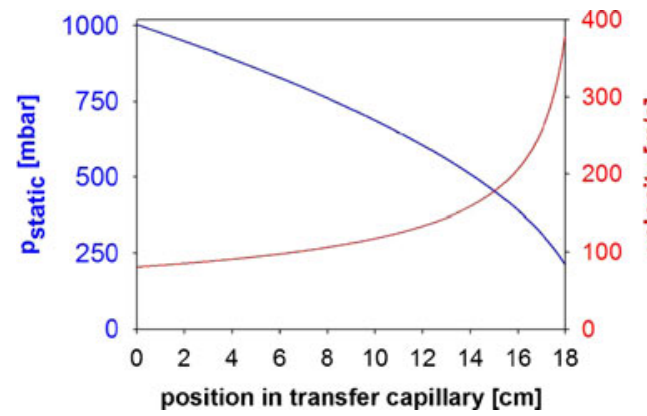

Figure 2. (Left) static pressure and velocity distribution within the transfer capillary, calculated for the following conditions: $d=$ $0.61 \mathrm{~mm}, \mathrm{Q}=1.41 \mathrm{l} / \mathrm{min}, \mathrm{p}_{0}=1003 \mathrm{mbar}, \mathrm{p}_{1}=3 \mathrm{mbar}$; (right) calculated dwell times for ions within the capillary as a function of the ionization position 
negative mode
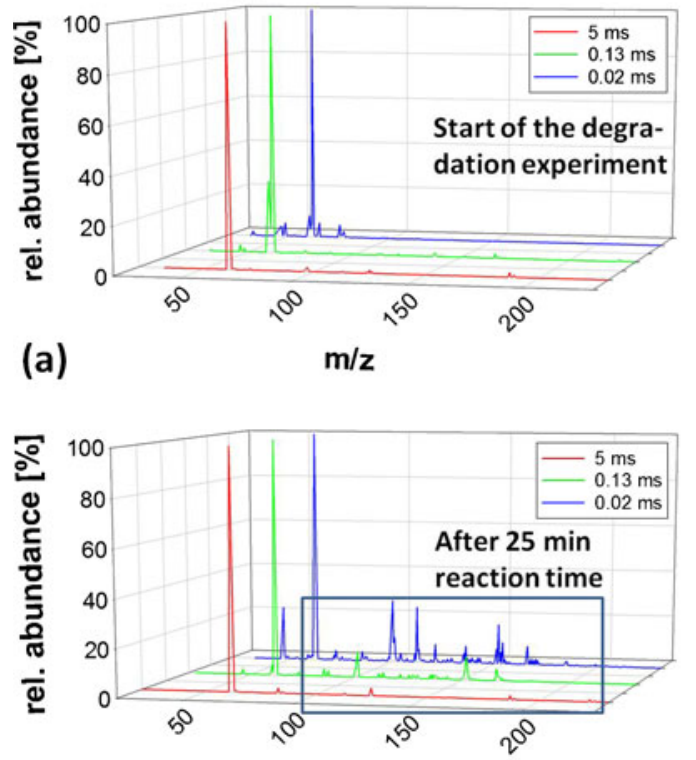

(b)

$\mathrm{m} / \mathbf{z}$

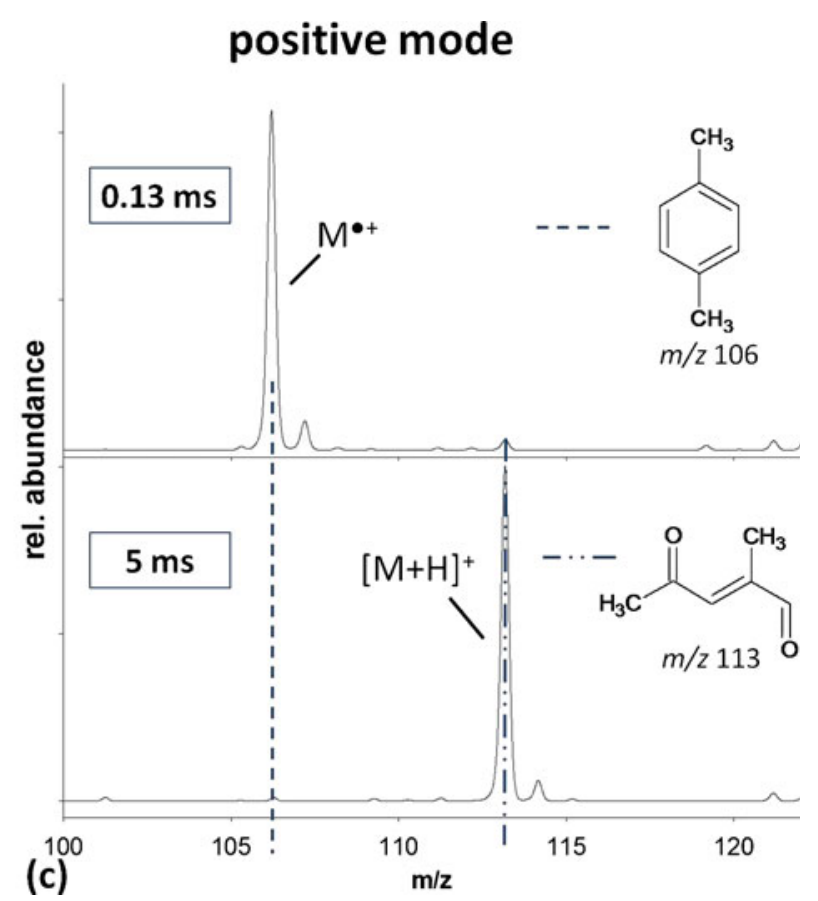

Figure 3. Mass spectra obtained at different ionization positions. The positions are denoted as $5 \mathrm{~ms}, 0.13 \mathrm{~ms}$, and $0.02 \mathrm{~ms}$ referring to the transit time between the ionization position and the capillary exit. (a) Comparison of negative ion mass spectra at the starting point of a degradation experiment with p-xylene (1 ppmV), MeONO (5 ppmV), and NO ( 3 ppmV) in synthetic air present; (b) comparison of negative ion mass spectra of the same degradation experiment after 25 min of reaction time; (c) comparison of positive ion mass spectra recorded at the $5 \mathrm{~ms}$ and $0.13 \mathrm{~ms}$ position, with identical p-xylene degradation composition present. The $\mathrm{m} / \mathrm{z}$ values on the right correspond to the nominal masses of the measured ions, as shown

time of a p-xylene degradation experiment ( 25 min run time) and thus reflect the same sample composition the only difference being the positions of ionization. The spectrum recorded upon ionizing at the $5 \mathrm{~ms}$ position leads to the conclusion that p-xylene $(\mathrm{m} / \mathrm{z} 106)$ has been quantitatively degraded. Consequently, the base peak appears at $\mathrm{m} / z 113$, assigned to the protonated molecule of the unsaturated 1,4dicarbonyl $\left(\left[\mathrm{C}_{6} \mathrm{H}_{9} \mathrm{O}_{2}\right]^{+}\right)$, which is one of the expected major degradation products[12]. However, the mass spectrum obtained at the $0.13 \mathrm{~ms}$ ionization position reveals that $\mathrm{m} / \mathrm{z}$ 106 for p-xylene is still the most abundant signal. This effect is readily explained by the considerable proton donor character of the ionized $\mathrm{p}$-xylene radical cation $\left(\left[\mathrm{C}_{8} \mathrm{H}_{10}\right]^{+}\right)$, potentially driving the following ion transformation process:

$$
\left[\mathrm{C}_{8} \mathrm{H}_{10}\right]^{+}+\mathrm{C}_{6} \mathrm{H}_{8} \mathrm{O}_{2} \rightarrow \mathrm{C}_{8} \mathrm{H}_{9} \cdot+\left[\mathrm{C}_{6} \mathrm{H}_{9} \mathrm{O}_{2}\right]^{+}
$$

A back of the envelope calculation is given to illustrate this situation. Recall that after $25 \mathrm{~min}$ run time of the degradation experiment roughly $50 \%$ of p-xylene is still present in the mixture. Starting with $1 \mathrm{ppmV}$ p-xylene yields a total of $500 \mathrm{ppbV}$ degradation products. Of the latter, the dicarbonyl $\mathrm{C}_{6} \mathrm{H}_{8} \mathrm{O}_{2}$ accounts for about 20\% (100 ppbV) as major product [12]. Assuming that the primary photoionization yield is $10^{-5}$ in the present setup, then around 5 pptV p-xylene radical cations are generated, ${ }^{2}$ i.e., the neutral dicarbonyl is in large excess. Thus the kinetics of
Rxn. 8 is first order with respect to p-xylene ions. Protonation, if thermodynamically favored is generally fast [45] and it is reasonable to assume a bimolecular rate constant for Rxn. 8 at the collision limit, i.e., $10^{-9} \mathrm{~cm}^{3}$ molecule $\mathrm{s}^{-1}$. Since $1 \mathrm{ppbV}$ correspond to $2.5 \cdot 10^{10}$ molecule $\mathrm{cm}^{-3}$ at $\mathrm{p}=1$ bar and $\mathrm{T}=298 \mathrm{~K}$, the life time of the p-xylene radical cations with respect to Rxn. 8 becomes

$$
\begin{aligned}
\tau_{\left[\mathrm{C}_{8} \mathrm{H}_{10}\right]^{++}} & =\frac{1}{k_{8} \times{ }_{C_{6} \mathrm{H}_{8} \mathrm{O}_{2}}} \\
& \tau_{\left[\mathrm{C}_{8} \mathrm{H}_{10}\right]^{++}}=\frac{1}{10^{-9} \frac{\mathrm{cm}^{3}}{\text { molecule } \mathrm{s}} \times 2.5 \cdot 10^{12} \frac{\mathrm{molecule}}{\mathrm{cm}^{3}}}=0.4 \cdot 10^{-3} \mathrm{~S}
\end{aligned}
$$

After $5 \tau$ less than $1 \%$ of the original p-xylene ion population is present in the mixture. Figure $3 \mathrm{c}$ verifies experimentally this estimate: After $\mathrm{t}=0.13 \mathrm{~ms}$. $(\mathrm{t}<\tau)$ only minor amounts of the dicarbonyl are protonated and a strong $\mathrm{p}$-xylene ion signal is detected, whereas after $5 \mathrm{~ms}(\mathrm{t}>10 \tau)$

\footnotetext{
${ }^{2}$ The ionization yield is estimated assuming a reasonable photonflux of $=$ $10^{15}$ photons/( $\left.\mathrm{s} \mathrm{cm}^{2}\right)$, a photoabsorption cross section of $\sigma=10^{-17} \mathrm{~cm}^{2}$ / molecule, an ionization quantum yield of $\varphi=1$ molecule/photon and an irradiation time of $t_{\text {irr }}=10^{-3} \mathrm{~s}$. Note that the assumption of a large excess of neutral dicarbonyl molecules over p-xylene radical cations would even hold true for ionization yields approaching $10^{-2}$, which is unreasonably high.
} 
the p-xylene ions have nearly quantitatively reacted away to form the protonated dicarbonyl and $\mathrm{C}_{8} \mathrm{H}_{9}$ neutral radicals.

In summary, the primarily generated ion population of $p$ xylene protonates the neutral degradation product population in subsequent ion-molecule reactions, i.e., the primary ion population of p-xylene is quantitatively consumed on the way to the collision-free region in favor of its own degradation products. Consequently, this superimposed ion-molecule chemistry leads to an apparently much faster degradation of p-xylene when analyzing the sample with $5 \mathrm{~ms}$ transit time.

\section{Characterization of the Custom Miniaturized VUV Lamp}

\section{Classification}

The type of discharge applied in the custom VUV lamp is classified as a high pressure ( $p_{\text {argon }}=200-1000$ mbar with gas flows of $100-500 \mathrm{~mL} / \mathrm{min}$ ), high frequency $(1.5-2.0 \mathrm{kHz})$, and medium voltage (500-1500 V) DC spark with pulse currents of $2 \mathrm{~A}$ and pulse durations of $7 \mu$ sWHM (cf. Figure $4 \mathrm{a}, \mathrm{b}$ ). The generated plasma is in a nonthermal and a nonequilibrated state, which consequently results in line spectra emission (cf. section: Optical Emission Spectroscopy (OES), further below). The basic working principle of the spark generation is typically used in spark optical emission spectroscopy [46]. Briefly, a capacitor $(2 \mathrm{nF})$, directly connected to the spark gap, is charged to the breakdown voltage $\mathrm{U}_{\text {break }}$ by a triggered switch-mode power supply. $U_{\text {break }}$ is a function of the electrode distance and shape, the characteristics of the surrounding gas species, the pressure within the discharge chamber, and the flow dynamics within the discharge region.

\section{Irradiation of the Gas Flow with and Without LiF Window}

For the present experiments, an open system with variable lamp pressure adjusted to the static pressure of the sample gas flow through the capillary was designed and embedded into the transfer capillary (cf. Figure 1 b). In this way, a virtually separated discharge region without any wavelength limitations was created. In addition to the VUV light, excited metastable

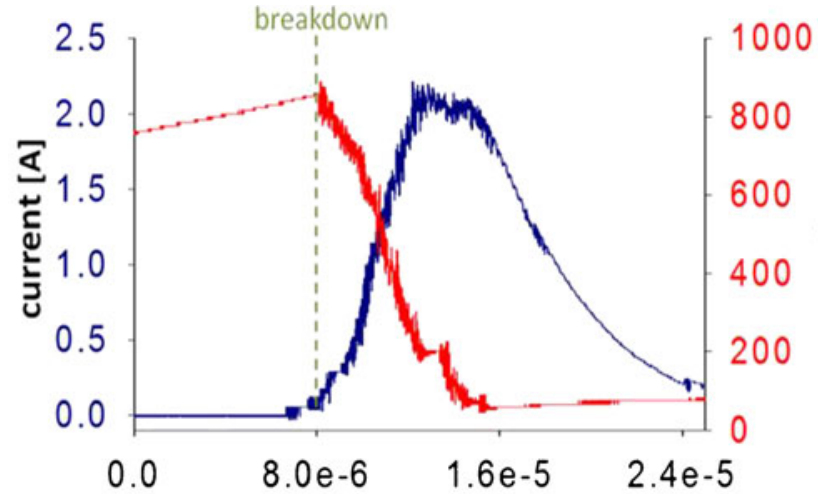

(a)

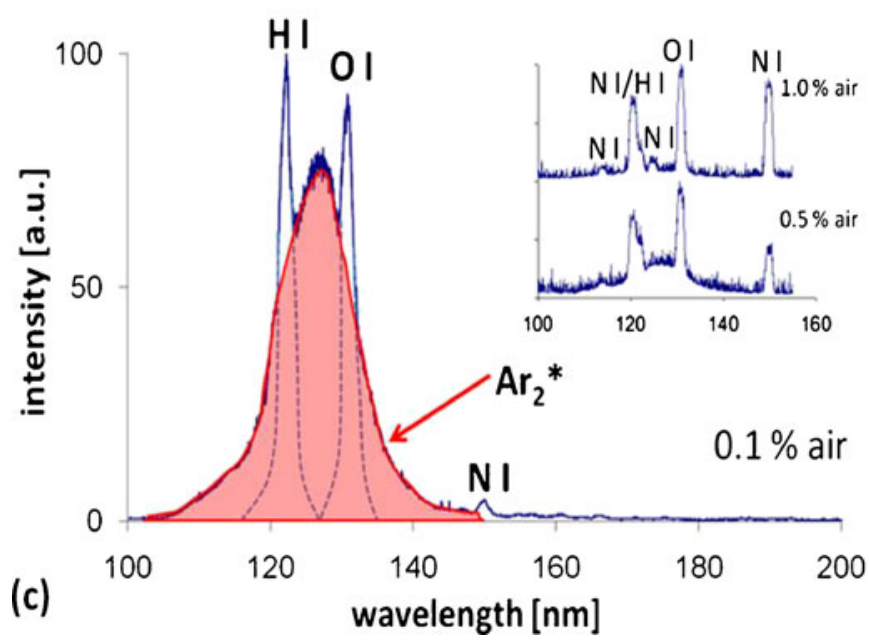

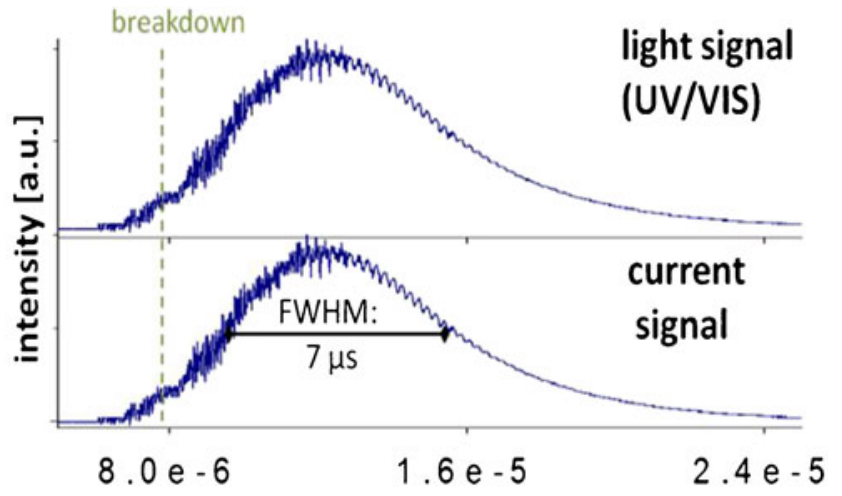

(b)

time $[s]$

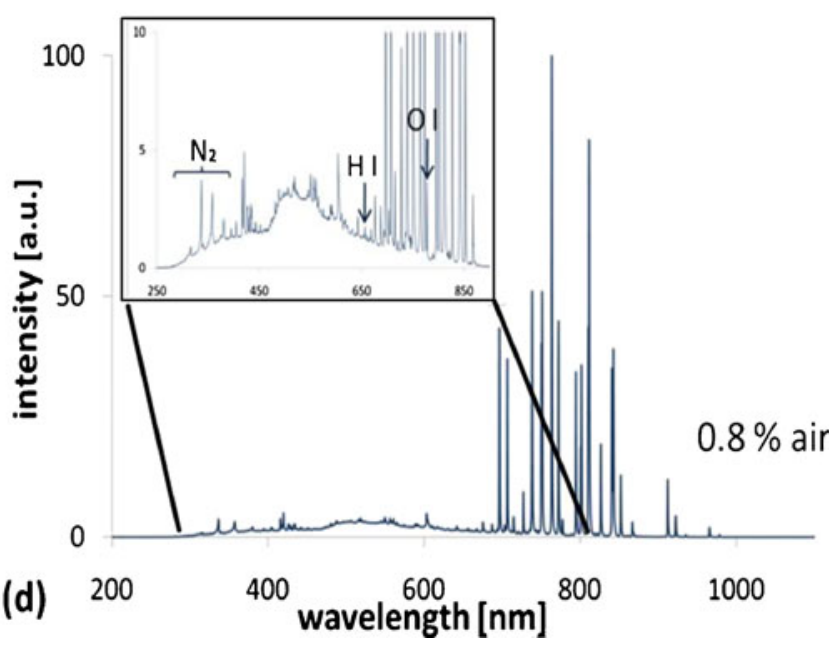

Figure 4. (a) Temporal evolution of the voltage and current during one spark; (b) temporal evolution of the current and the light emission in the UV/VIS during one spark; (c) VUV spectra of the spark discharge in 1000 mbar argon with $0.1 \%, 0.5 \%$, and $1.0 \%$ synth. air; (d) UV/VIS spectrum of the spark discharge in 720 mbar argon with $0.8 \%$ synth. air 
rare gas species have to be considered in such open systems $\left(\mathrm{Ar}^{*}: 11.55\right.$ and $11.72 \mathrm{eV}$ ) as well and ought to be investigated with respect to impacting on the ionization mechanisms. Due to a slight increase in temperature at the point of the discharge (glass cover maximal temperature: $323 \mathrm{~K}$ ) the impact of the operating lamp on the sample gas flow into the MS was investigated and revealed that the total gas flow increased by max. $4 \%$ with the discharge running. Calibrated monitoring of the $\mathrm{O}_{2}$ and $\mathrm{N}_{2}$ concentrations within the lamp [cf. section: Optical emission spectroscopy (OES)] gave valuable information about the gas composition within the discharge region. It is demonstrated that impurities such as $\mathrm{O}_{2}$ are kept below $0.2 \%$ in the discharge region of this windowless design when the lamp pressure is carefully adjusted to the static pressure, even with synthetic air sampled through the transfer capillary.

\section{Optical Emission Spectroscopy (OES)}

Figure $4 \mathrm{c}, \mathrm{d}$ show optical emission spectra of the spark discharge lamp in the wavelength range 105 to $1100 \mathrm{~nm}$. Note that wavelength dependent transmission discrimination of the fiber optic and the LiF window of the VUV spectrometer are not considered. The UV/VIS spectrum in Figure 4d shows the emission of the discharge lamp when positioned at the center $(9 \mathrm{~cm})$ of the transfer capillary (argon pressure $=720 \mathrm{mbar}$ ), which corresponds to the static pressure of the synthetic air gas flow through the capillary at that position. The spectrum is dominated by characteristic Ar I lines (argon in the neutral state), of which the most intense are listed in Table S1 in the Supplemental Material. The Grotrian diagram for Ar I [47] shows that many of these lines between 390 and $1100 \mathrm{~nm}$ are precursor emissions for transitions in the $\operatorname{VUV~}\left({ }^{2}[3 / 2]^{*} \mathrm{~J}=1 \rightarrow\right.$ ${ }^{1} \mathrm{~S}_{0}=106.7$ and $\left.{ }^{2}[1 / 2]^{*} \mathrm{~J}=1 \rightarrow{ }^{1} \mathrm{~S}_{0}=104.8 \mathrm{~nm}\right)$ and further indicate the formation of highly excited metastable argon species $\left(\operatorname{Ar}^{*}\left({ }^{2}[3 / 2]^{*} \mathrm{~J}=0\right)=11.55 \mathrm{eV}\right.$ and $\left.\operatorname{Ar}^{*}\left({ }^{2}[1 / 2]^{*} \mathrm{~J}=0\right) 11.72 \mathrm{eV}\right)$. Generally, these precursor emissions allow indirect monitoring of the VUV radiation intensity and extent of metastable formation. The spectrum further shows the emissions from electronically excited $\mathrm{N}_{2}$ (six bands from 280 to $400 \mathrm{~nm}$ ), O I $(777 \mathrm{~nm})$ and $\mathrm{H} \mathrm{I}(656 \mathrm{~nm})$, which result from diffusion of the bulk gas flow into the discharge region. The air concentration within the argon atmosphere amounts to $0.8 \%$ determined by calibrating the relative intensity of the O I (777 nm) and Ar I $(763 \mathrm{~nm})$ lines against added concentrations of synthetic air. The broad continuum between 250 and $700 \mathrm{~nm}$ is tentatively assigned to free-free and free-bound transitions of the present electrons.

The VUV spectrum at an argon pressure of 1000 mbar containing only $0.1 \%$ air (cf. Figure $4 \mathrm{c}$ ) is characterized by the second excited argon dimer $\operatorname{Ar}_{2}{ }^{*}\left({ }^{1} \Sigma_{\mathrm{u}}^{+}\right.$and $\left.{ }^{3} \Sigma_{\mathrm{u}}^{+}\right)$continuum centered at $127 \mathrm{~nm}$, with a line width of FWHM $=20 \mathrm{~nm}$, and three lines that are assigned to H I $(121.5 \mathrm{~nm})$, O I $(130.5 \mathrm{~nm})$, and $\mathrm{N} \mathrm{I}(149 \mathrm{~nm})$ transitions. However, the predicted VUV lines from UV/VIS precursor emissions at 106.7 and $104.8 \mathrm{~nm}$ do not appear. The radiation of the latter transition is most likely absorbed by the LiF window of the VUV spectrometer, therefore windowless VUV intensity measurements are planned. The absence of the ${ }^{2}[3 / 2]^{*} \mathrm{~J}=1$ emission to the ground state $(106.7 \mathrm{~nm})$ is also partially assigned to the reduced transmission of the window ( $25 \%$ [30]) but moreover this state is primarily quenched to form argon excimers $\operatorname{Ar}_{2}{ }^{*}\left({ }^{1} \Sigma_{\mathrm{u}}{ }^{+}\right)$ with argon ground state $\operatorname{Ar}\left({ }^{1} \mathrm{~S}_{\mathrm{o}}\right)$ atoms, as described by Millet et al. [23]:

$$
\begin{gathered}
\operatorname{Ar}^{*}\left({ }^{2}[3 / 2] * \mathrm{~J}=1\right)+2 \operatorname{Ar}\left({ }^{1} \mathrm{~S}_{\mathrm{o}}\right) \\
\rightarrow \operatorname{Ar}_{2}{ }^{*}\left({ }^{1} \Sigma^{+}{ }_{\mathrm{u}}\right)+\operatorname{Ar}\left({ }^{1} \mathrm{~S}_{\mathrm{o}}\right)
\end{gathered}
$$

(Rxn.9)

They further proposed a pathway to form the triplet state of the argon excimer $\operatorname{Ar}_{2}{ }^{*}\left({ }^{3} \Sigma_{\mathrm{u}}{ }^{+}\right)$via:

$$
\begin{gathered}
\operatorname{Ar}^{*}\left({ }^{2}[3 / 2] * \mathrm{~J}=0\right)+2 \operatorname{Ar}\left({ }^{1} \mathrm{~S}_{\mathrm{o}}\right) \\
\rightarrow \operatorname{Ar}_{2}{ }^{*}\left({ }^{3} \Sigma^{+}{ }_{\mathrm{u}}\right)+\operatorname{Ar}\left({ }^{1} \mathrm{~S}_{\mathrm{o}}\right)
\end{gathered}
$$

Here the metastable state $\operatorname{Ar}^{*}\left({ }^{2}[3 / 2]^{*} \quad J=0\right)$ at $11.55 \mathrm{eV}$ reacts in a three body collision process with argon atoms in the ground state to generate the excited dimer. It is noteworthy that the metastable state itself is believed to be an inactive ionizing species within the applied operation mode of this setup, since the discharge region is effectively separated from the sample gas flow (see above) and thus collisions with the analyte are unlikely. However, reaction 10 turns this inactive species into a possibly radiative excimer, hence an active ionizing species. Taking into account the relative intense precursor emission $(\sim 30 \%$, c.f. Table S1 in the Supplementary Information) in the UV/VIS leading to this metastable state, this reaction is speculated to be very important for the total ionization efficiency of this lamp. The radiative transition of both excimer states to the dissociative ground state is centered at $127 \mathrm{~nm}$. The reported lifetimes are $\tau_{\text {singlet }}=6 \mathrm{~ns}$ and $\tau_{\text {triplet }}=2.86 \mu$ s for $\operatorname{Ar}_{2}{ }^{*}\left({ }^{1} \Sigma_{\mathrm{u}}{ }^{+}\right)$[48] and $\operatorname{Ar}_{2}{ }^{*}\left({ }^{3} \Sigma_{\mathrm{u}}{ }^{+}\right)$[23], respectively. Due to the long lifetime of the latter, resonant quenching of the excimer by $\mathrm{O} \mathrm{I}, \mathrm{N} \mathrm{I}$, and $\mathrm{H} \mathrm{I}$ is enhanced as, e.g., described for oxygen by Moselhy et al. [49]. The spectra in Figure $4 \mathrm{c}$ with $0.5 \%$ and $1.0 \%$ air present in 1000 mbar of Argon clearly demonstrate the quenching effect of small amounts of impurities. The excimer continuum completely disappears in favor of $\mathrm{H} \mathrm{I}$ $(121.5 \mathrm{~nm}), \mathrm{O} \mathrm{I}(130.5 \mathrm{~nm})$ and $\mathrm{N} \mathrm{I}(113,120,124$, and $149 \mathrm{~nm}$ ), however, the integrated spectral intensity from 105 to $155 \mathrm{~nm}$ remains approximately constant. This result is supported by an investigation of the ionization efficiency using acetone in which $\mathrm{O}_{2}$ was added stepwise to the argon atmosphere of the lamp. The MS signal intensity remained virtually constant even with up to $10 \%$ oxygen present. Pure oxygen, however, caused a considerable decrease in the MS signal, apparently due to 
a significant change in the discharge characteristics itself. The above proposed VUV monitoring of UV/VIS precursor emissions is thus complicated by the subsequent, complex discharge chemistry following the spark breakdown. Nevertheless, all involved species do show concentration dependent lines between 200 and $1100 \mathrm{~nm}$, thus monitoring is still possible and will be worked out in detail in future work.

Measurements with the commercially available krypton radio frequency (Kr-rf) lamp (116 and $124 \mathrm{~nm}$ ), typically used for APPI MS, showed that the total VUV radiation $(>8.3 \mathrm{eV})$ of the custom spark discharge lamp amounts to $75 \%$ of the Kr-rf lamp emission. It is noted that the radiation at $104.8 \mathrm{~nm}$ (precursor emission accounts for $13.5 \%$, cf. Table S1 in the Supplemental Material) and discrimination of wavelengths below $116 \mathrm{~nm}$ due to the $\mathrm{LiF}$ window of the VUV spectrometer are not considered. In the windowless lamp design, however, this radiation is quantitatively available for ionization.

Figure $4 \mathrm{~b}$ shows the temporal evolution of the UV/VIS light pulse compared to the time dependent current distribution. The slopes are nearly identical, demonstrating that on the sub- $\mu$ s timescale, no time delays between the discharge breakdown and radiative processes in the UV/VIS occur. Additional experiments (not shown here) also demonstrated synchronized emission between the UV/VIS and VUV radiation.

Determination of Limits of Detection For the LOD experiments the mass spectrometer was run in the same mode as for a typical degradation product study, allowing for direct comparisons of the performance in real-world analytical applications for which this setup is intended. Thus, the MS was operated in the alternating mode, with 5 and $20 \mathrm{~ms}$ accumulation time for the positive and negative ion mode, respectively. One data point in the chromatogram is the result of 10 averaged single spectra, thus every $250 \mathrm{~ms}$ one data point for each mode was recorded. The mass range was set from $\mathrm{m} / \mathrm{z} 15$ to 500 .
The LODs for benzene $\left([\mathrm{M}]^{+}, \mathrm{m} / \mathrm{z} 78\right)$, and 2-butanone $\left([\mathrm{M}+\mathrm{H}]^{+}, m / z\right.$ 73) were estimated following the procedure described by Kaiser and Specker [50] Equation (7),

$$
x_{L O D}=\frac{3 \sigma}{b}
$$

with $x_{L O D}$ as the lowest analyte concentration being detected with a statistical probability of $99.7 \%, \sigma$ as the standard deviation of several measurements without analyte being present and with $b$ the slope of a calibration line. The standard deviations were determined from a 5 min run of a single ion chromatogram with no analyte present. The slopes of the linear regressions result in LODs of $0.5 \mathrm{ppbV}$ for benzene (coefficient of determination $\mathrm{R}^{2}=0.997$ ) and $0.1 \mathrm{ppbV}$ for 2-butanone $\left(\mathrm{R}^{2}=0.998\right)$ at a temporal resolution $<1 \mathrm{~s}$, respectively.

Application in Real Time Degradation Product Studies So far the characterized cAPPI-MS setup has been applied to several degradation product studies. One example is given in Figure 5, where p-xylene has been degraded with $\mathrm{OH}$ radicals in the presence of $\mathrm{NO}_{\mathrm{x}}$. Shown are the single ion chromatograms of the parent molecule and of three selected products, 2,5-dimethyl-phenol at $\mathrm{m} / \mathrm{z} 122$, methylglyoxal as $[\mathrm{M}+\mathrm{H}]^{+}$at $m / z 73$ and an unsaturated 1,4-dicarbonyl as its $[\mathrm{M}+\mathrm{H}]^{+}$at $m / z 113$. It follows that this setup is capable of monitoring the temporal evolution of the degradation experiment in the positive as well as in the negative ion mode. Detailed investigations concerning degradation product studies will be presented in an forthcoming paper [51].

The discharge lamp showed high temporal stability throughout all the experiments. Additionally, a $10 \mathrm{~h}$ run with the discharge continuously operating has been performed. In this experiment, acetone was injected into the photoreactor and backfilled with synthetic air, resulting in a mixing ratio of $300 \mathrm{ppbV}$. In order to maintain a constant pressure, the reactor was continuously filled with synthetic air, which matched the outflow to the mass spectrometer. A

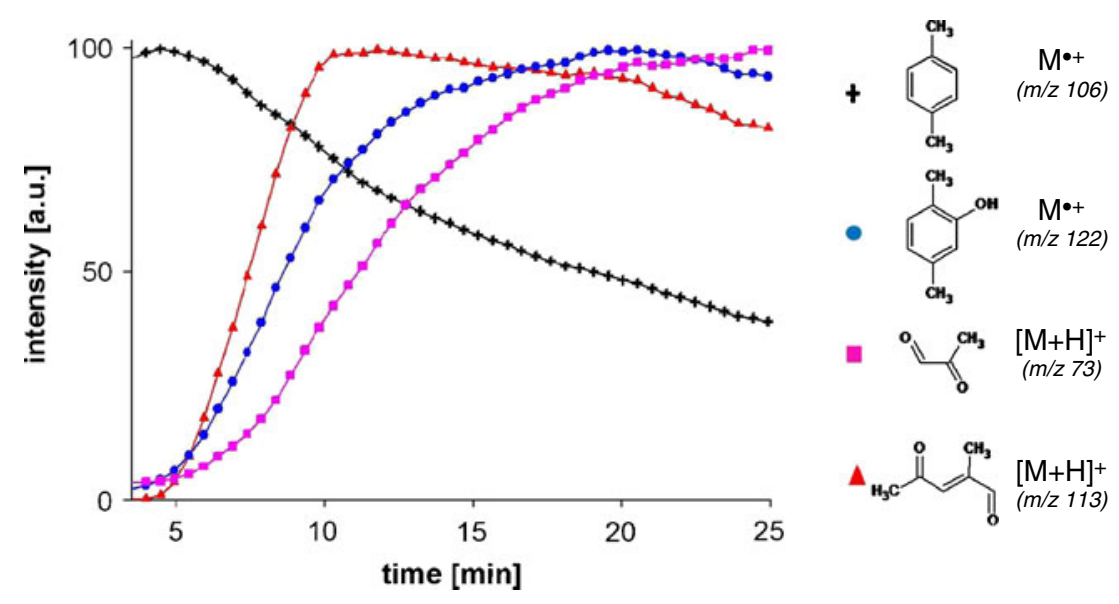

Figure 5. Example of a degradation experiment with the novel APPI-MS setup. Shown are the smoothed single ion chromatograms of the parent molecule ( $p$-xylene) and three selected products 
$42 \%$ decrease in the initial concentration was calculated for a $10 \mathrm{~h}$ run; the MS signal intensity showed a $41 \%$ decrease, respectively, which is an excellent agreement.

\section{Summary and Conclusion}

We have presented a novel cAPPI-MS setup that significantly reduces secondary ion transformation processes and thus preserves mass spectrometric information whilst the ionization still takes place at appreciable analyte density.

The turbulent nature of the capillary gas flow allows significant manipulation of the inner capillary wall geometry without affecting the flow properties. In the present setup, a hole was drilled into the capillary body. This port may be used for static pressure measurements or as an optical port for VUV radiation. The position of the hole is freely selectable, provided the transfer stage of the mass spectrometer provides corresponding access to the capillary.

Various types of VUV lamps may be coupled to the manipulated capillary, however, the windowless approach presented in this work using a miniaturized spark discharge lamp as radiation source allows for maximum flexibility: (1) if the pressure inside the lamp discharge chamber is maintained at the same pressure as the (measured) static pressure at the capillary hole, then VUV photons appear to be the sole source of primary ionization, (2) upon using different discharge gases, much shorter or longer wavelengths as obtained from the Ar dimers may be generated, (3) increasing the discharge region pressure, reactive species such as metastables may be coupled into the analyte gas stream, resulting in alternative ionization processes (e.g., Penning or charge transfer ionization).

Selecting an ionization region at the downstream end of the capillary drastically reduces ion dwell times. As a result, even ion molecule reactions with collision controlled rate constants are strongly suppressed (kinetic control), despite the high local pressure. Thus, the ion population detected more closely represents the neutral gas composition compared with populations generated in conventional large volume API sources. In the latter case, thermodynamically controlled, i.e., fully thermally equilibrated ion populations are recorded, which may substantially differ from the neutral gas composition.

With respect to atmospheric degradation studies it is noted that the experimental conditions (temperature, pressure) in the entire gas sampling stage including the transfer capillary are nearly identical to those typically used within the smog chamber. Thus, sampling artifacts caused by equilibrium shifts are strongly reduced.

So far, this cAPPI-MS setup has been successfully applied to several degradation product studies of volatile organic compounds. It showed high reproducibility and stability, e.g., demonstrated in a $10 \mathrm{~h}$ long term run. Future work focuses on the systematic studies of atmospheric degradation experiments using cAPPI. Furthermore, other API methods, i.e., atmospheric pressure laser ionization
(APLI) as well as atmospheric pressure electron capture ionization (APEC) are currently designed to operate directly on the transfer capillary flow.

\section{Acknowledgments}

The authors gratefully acknowledge financial support of this work by the German Research Foundation (DFG) within project POXSA (BE 2124/4-1).

\section{References}

1. Seinfeld, J.H., Pandis, S.N.: Atmospheric Chemistry and PhysicsFrom Air Pollution to Climate Change. John Wiley and Sons, Inc, New York, NY, USA (1998)

2. Atkinson, R., Arey, J.: Atmospheric degradation of volatile organic compounds. Chem. Rev. 103, 4605-4638 (2003)

3. Volkamer, R., Platt, U., Wirtz, K.: Primary and secondary glyoxal formation from aromatics: experimental evidence for the bicycloalkylradical pathway from Benzene, Toluene, and p-Xylene. J. Phys. Chem. 105, 7865-7874 (2001)

4. Volkamer, R., Klotz, B., Barnes, I., Imamura, T., Wirtz, K., Washida, N., Becker, K.H., Platt, U.: OH-initiated oxidation of benzenePart I. Phenol formation under atmospheric conditions. Phys Chem Chem Phy 4, 1598-1610 (2002)

5. Klotz, B., Barnes, I., Becker, K.H.: New results on the atmospheric photooxidation of simple alkylbenzenes. Chem. Phys. 231, 289-301 (1998)

6. Olariu, R.I., Klotz, B., Barnes, I., Becker, K.H., Mocanu, R.: FT-IR study of the ring-retaining products from the reaction of $\mathrm{OH}$ radicals with phenol, o-, m-, and p-cresol. Atmos. Environ. 36, 3685-3697 (2002)

7. Klotz, B., Barnes, I., Becker, K.H., Golding, B.T.: Atmospheric chemistry of benzene oxide/oxepin. J. Chem. Soc. Faraday Trans. 93, 1507-1516 (1997)

8. Bohn, B.: Formation of peroxy radicals from $\mathrm{OH}-$ Toluene adducts and $\mathrm{O}_{2}$. J. Phys. Chem. A 105, 6092-6101 (2001)

9. Bohn, B., Zetzsch, C.: Gas-phase reaction of the $\mathrm{OH}-$ benzene adduct with $\mathrm{O}_{2}$ : reversibility and secondary formation of $\mathrm{HO}_{2}$. Phys. Chem. Chem. Phys. 1, 5097-5107 (1999)

10. Smith, D.F., McIver, C.D., Kleindienst, T.E.: Primary product distribution from the reaction of hydroxyl radicals with toluene at ppb $\mathrm{NO}_{\mathrm{x}}$ mixing ratios. J. Atmos. Chem. 30, 209-228 (1998)

11. Yu, J., Jeffries, H.E., Sexton, K.G.: Atmospheric photooxidation of alkylbenzenes-I. Carbonyl product analyses. Atmos. Environ. 31, 2261-2280 (1997)

12. Arey, J., Obermeyer, G., Aschmann, S.M., Chattopadhyay, S., Cusick, R.D., Atkinson, R.: Dicarbonyl products of the $\mathrm{OH}$ radical-initiated reaction of a series of aromatic hydrocarbons. Environ. Sci. Technol. 43, 683-689 (2008)

13. Yu, J., Jeffries, H.E.: Atmospheric photooxidation of alkylbenzenesII. Evidence of formation of epoxide intermediates. Atmospheric Environment. 31, 2281-2287 (1997)

14. Le Page, V., Keheyan, Y., Bierbaum, V.M., Snow, T.P.: Chemical constraints on organic cations in the interstellar medium. J. Am. Chem. Soc. 119, 8373-8374 (1997)

15. Le Page, V., Keheyanb, Y., Snowa, T.P., Bierbaum, V.M.: Gas phase chemistry of pyrene and related cations with molecules and atoms of interstellar interest. Int. J. Mass Spectrom. 187, 949-959 (1999)

16. Lorenz, M.; Wißdorf, W.; Klee, S.; Kersten, H.; Brockmann, K. J.; Benter, T.: Spatially and temporally resolved atmospheric pressure laser ionization as a powerful tool for the characterization of ion sources: An overview. Proceedings of the 58th ASMS Conference on Mass Spectrometry and Allied Topics; Salt Lake City, UT, USA (May 2010)

17. Lorenz, M., Wissdorf, W., Klee, S., Kersten, H., Brockmann, K. J., Benter, T.: Ion Transport Processes in API Sources: Temporally and Spatially Resolved APLI Measurements. Proceedings of the 57th ASMS Conference on Mass Spectrometry and Allied Topics; Philadelphia, PA, USA (June 2009) 
18. Carroll, D.I., Dzidic, I., Horning, E.C., Stillwell, R.N.: Atmospheric pressure ionization mass spectrometry. Appl. Spectrosc. Rev. 17, 337406 (1981)

19. Kersten, H., Funcke, V., Lorenz, M., Brockmann, K.J., Benter, T., O'Brien, R.: Evidence of neutral radical induced analyte ion transformations in APPI and Near-VUV APLI. J. Am. Soc Mass Spectrom. 20, 1868-1880 (2009)

20. Hanna, S.J., Campuzano-Jost, P., Simpson, E.A., Robb, D.B., Burak, I., Blades, M.W., Hepburn, J.W., Bertram, A.K.: A new broadly tunable (7.4-10.2 eV) laser based VUV light source and its first application to aerosol mass spectrometry. Int. J. Mass Spectrom 279, 134-146 (2009)

21. Mühlberger, F., Wieser, J., Ulrich, A., Zimmermann, R.: Single photon ionization (SPI) via incoherent VUV-excimer light: Robust and compact time-of-flight mass spectrometer for on-line, real-time process gas analysis. Anal. Chem. 74, 3790-3801 (2002)

22. Efthimiopoulos, T., Zouridis, D., Ulrich, A.: Excimer emission spectra of rare gas mixtures using either a supersonic expansion or a heavy-ionbeam excitation. J. Phys. D Appl. Phys. 30, 1746-1754 (1997)

23. Millet, P., Birot, A., Brunet, H., Dijolis, H., Galy, J., Salamero, Y.: Spectroscopic and kinetic analysis of the VUV emissions of argon and argon-xenon mixtures. I. Study of pure argon. J Phys. B Atomic Mol. Phys. 15, 2935-2944 (1982)

24. Wieser, J., Murnick, D.E., Ulrich, A., Huggins, H.A., Liddle, A., Brown, W.L.: Vacuum ultraviolet rare gas excimer light source. Rev. Sci. Instrum. 68, 1360-1364 (1997)

25. Jensen, C.A., Libby, W.F.: Intense 584- $\AA$ light from a simple continuous helium plasma. Phys. Rev. 135, 1247-1252 (1964)

26. Moselhy, M., Schoenbach, K. H.: Excimer emission from cathode boundary layer discharges. J. Appl. Phys. 95(2004)

27. Gellert, B., Kogelschatz, U.: Generation of excimer emission in dielectric barrier discharges. Appl. Phys. B Lasers Optics. 52, 14-21 (1991)

28. Kogelschatz, U.: Silent discharges for the generation of ultraviolet and vacuum ultraviolet excimer radiation. Pure Appl. Chem. 62, 1667-1674 (1990)

29. Sankaran, R.M., Giapis, K.P., Moselhy, M., Schoenbach, K.H.: Argon excimer emission from high-pressure microdischarges in metal capillaries. App. Phys. Lett. 83, 4728-4730 (2003)

30. Knop, H., Uhrig, M., Berkemeier, M., Becker, K., Hanne, G.F.: A temperature-stabilized LiF line filter for the argon $106.7 \mathrm{~nm}$ resonance line. Meas. Sci. Technol. 8, (1997)

31. Inn, E.C.Y.: Vacuum ultraviolet spectroscopy: A review. Spectrochim. Acta 7, 65-87 (1955)

32. Duncanson, A., Stevenson, R.W.H.: Some properties of magnesium fluoride crystallized from the melt. Proceedings of the Physical Society. 72, $1001(1958)$

33. Blatt, A.H.: Organic Synthesis, vol. 2. Wiley, New York, NY, USA (1943)

34. Olariu, R.I., Bejan, I., Barnes, I., Klotz, B., Becker, K.H., Wirtz, K.: Rate coefficients for the gas-phase reaction of $\mathrm{NO}_{3}$ radicals with selected dihydroxybenzenes. In. J. Chem. Kinet. 36, 577-583 (2004)

35. Barnes, I., Becker, K.H., Mihalopoulos, N.: An FTIR product study of the photooxidation of dimethyl disulfide. J. Atmos. Chem. 18, 267-289 (1994)
36. Barnes, I., Kersten, H., Wissdorf, W., Pöhler, T., Hönen, H., Klee, S., Brockmann, K.J., Benter, T.: Novel Laminar Flow Ion Sources for LCand GC-API MS. Proceedings of the 58th ASMS Conference on Mass Spectrometry and Allied Topics; Salt Lake City, UT, USA (May 2010)

37. Constapel, M., Schellenträger, M., Schmitz, O.J., Gäb, S., Brockmann, K.J., Giese, R., Th, B.: Atmospheric-pressure laser ionization: a novel ionization method for liquid chromatography/mass spectrometry. Rapid Commun. Mass Spectrom. 19, 326-336 (2005)

38. Schiewek, R., Lorenz, M., Giese, R., Brockmann, K., Benter, T., Gäb, S., Schmitz, O.: Development of a multipurpose ion source for LC-MS and GC-API MS. Anal. Bioanal. Chem. 392, 87-96 (2008)

39. Schiewek, R., Schellenträger, M., Mönnikes, R., Lorenz, M., Giese, R., Brockmann, K.J., Gäb, S., Benter, T., Schmitz, O.J.: Ultrasensitive determination of polycyclic aromatic compounds with atmosphericpressure laser ionization as an interface for GC/MS. Anal. Chem. 79, 4135-4140 (2007)

40. Kersten, H., Lorenz, M., Brockmann, K., Benter, T.: Evaluation of the performance of small diode pumped UV solid state (DPSS) Nd:YAG lasers as new radiation sources for atmospheric pressure laser ionization mass spectrometry (APLI-MS). J. Am. Soc. Mass Spectrom. 22, 10631069 (2011)

41. Kersten, H., Wissdorf, W., Brockmann, K.J., Benter, T., O'Brien, R.: VUV photoionization within transfer capillaries of atmospheric pressure ion sources. Proceedings of the 58th ASMS Conference on Mass Spectrometry and Allied Topics; Salt Lake City, UT, USA (2010)

42. Wutz, M., Adam, H., Walcher, W.: Theorie und Praxis der Vakuumtechnik. 4th ed.; Friedr. Vieweg und Sohn: Braunschweig/Wiesbaden, Germany (1988)

43. Michalke, A.: Beitrag zur Rohrströmung kompressibler Fluide mit Reibung und Wärmeübergang. Arch. Appl. Mech. 57, 377-392 (1987)

44. Klopotowski, S., Brachthaeuser, Y., Mueller, D., Kersten, H., Wissdorf, W., Derpmann, V., Klee, S., Brockmann, K.J., Janoske, U., Gregor, H., Benter, T.: API-MS Transfer Capillary Flow: Examination of the Downstream Gas Expansion. Proceedings of the 59th ASMS Conference on Mass Spectrometry and Allied Topics; Denver, CO, USA (June 2011)

45. Anicich, V.G.: An Index of the Literature for Bimolecular Gas Phase Cation-Molecule Reaction Kinetics. JPL Publication 03-19. (2003)

46. Laqua, K.: Emissionsspektroskopie in Ullmanns Enczklopädie der technischen Chemie. Kelker, H. Verlag Chemie, 5 (25). 4, 441-500, Weinheim (1980)

47. Ralchenko, Y., Kramida, A.E., Reader, J., NISTASDTeam(2008) NIST Atomic Spectra Database (version 3.1.5); http://physics.nist.gov/asd3. (2010)

48. Koehler, H.A., Ferderber, L.J., Redhead, D.L., Ebert, P.J.: Vacuumultraviolet emission from high-pressure xenon and argon excited by high-current relativistic electron beams. Phys. Rev. A 9, 768 (1974)

49. Moselhy, M., Stark, R.H., Schoenbach, K.H., Kogelschatz, U.: Resonant energy transfer from argon dimers to atomic oxygen in microhollow cathode discharges. Appl. Phys. Lett. 78, 880-882 (2001)

50. Kaiser, H., Specker, H.: Bewertung und Vergleich von Analysenverfahren. Fresenius J. Anal. Chem. 149, 46-66 (1956)

51. Kersten, H., Barnes, I., Brockmann, K. J., Benter, T.: to be published. (2011) 